\title{
O DESENVOLVIMENTO NO BRASIL A PARTIR DA REVOLUÇÃO DE 1930 E SEUS IMPACTOS SOCIOAMBIENTAIS: TRANSFORMAÇÃO ECONÔMICA E SUSTENTABILIDADE
}

\author{
Romina Ysabel Bazán Barba* \\ Nivaldo dos Santos ${ }^{* *}$
}

\begin{abstract}
Resumo
Aborda-se, no Direito e no campo da sustentabilidade, pela vertente histórico-jurídico, a problemática do desenvolvimento do Brasil a partir da Revolução de 1930. Através do método dedutivo, buscou-se compreender o desenvolvimentismo nacional, o processo de desenvolvimento industrial, a transformação econômica e seus impactos socioambientais. $\mathrm{O}$ objetivo deste estudo está na análise do processo de industrialização tratando das mercadorias fictícias, em destaque, a terra, como também impactos do desenvolvimento no meio ambiente, considerando-se a sustentabilidade. Por fim, traz-se um debate da história do desenvolvimento econômico e tecnológico do Brasil - com vista as discussões teóricas - com o atual quadro vivenciado.
\end{abstract}

Palavras-chave: Desenvolvimento; Sustentabilidade; Mercadorias fictícias; Meio ambiente; Transformação econômica.

\section{DEVELOPMENT IN BRAZIL FROM THE 1930 REVOLUTION AND ITS SOCIAL AND ENVIRONMENTAL IMPACTS: ECONOMIC TRANSFORMATION AND SUSTAINABILITY}

\begin{abstract}
In the Law and in the sustainability field, the historical-juridical aspects addresses the problematic of the development of Brazil from the 1930 Revolution. Through the deductive method, we sought to understand national developmentalism, the process of industrial development, economic transformation and its social and environmental impacts. The aim of this study is the analysis of the industrialization process dealing with fictitious commodities, especially land, impacts of development on the environment, considering sustainability. Finally, there is a debate on the history of economic and technological development in Brazil - with a view to theoretical discussions - with the current situation experienced.
\end{abstract}

Keywords: Development; Sustainability; Fictitious goods; Environment; Economic transformation.

\section{Introdução}

\footnotetext{
*Advogada. Mestre em Direito pelo Programa de Pós-Graduação em Direito Agrário da UFG. Especializanda em Direito Civil e Processo Civil pela ATAME-GO. Membro da Comissão de Direito Agrário da OAB-GO. E-mail: rominabazan92@gmail.com. <http://lattes.cnpq.br/3253119728025866>

** Doutor em Direito pela PUC/SP. Possui financiamento pela FAPEG e IPOGDATA. Professor titular na PUC/GO e UFG. Secretário especial de Ciência e Tecnologia do Instituto Goiano de Direito Ambiental. E-mail: nivaldodossantos@bol.com.br.<http://lattes.cnpq.br/3359203015249134>
} 
Tendo em vista a vertente metodológica histórico-jurídico na realização da presente pesquisa, tem-se como objetivo geral a compreensão do desenvolvimento do Brasil a partir da Revolução de 1930, analisando-se o processo de industrialização tratando das mercadorias fictícias e dos impactos sociais e ambientais decorrentes desse desenvolvimento econômico e tecnológico.

Visa-se com este estudo analisar de maneira dinâmica, transdisciplinar e intertextual as mudanças ocorridas na sociedade sobre o tema pesquisado, com o intuito de formar conhecimento sobre o passado, fazer conclusões sobre o presente e imaginar um futuro provável. Assim, para compreender a realidade contemporânea é mister introduzir algumas considerações preliminares.

A sociedade antes da Revolução Industrial era essencialmente agrária, pois estava composta de agricultores e mercadores que compravam e vendiam os produtos extraídos da terra. Com o surgimento e a utilização das máquinas no sistema de produção agrícola, ocorre a ampliação da quantidade de mercadorias produzidas, com o fim de que a produção fosse rentável devido ao alto custo das máquinas. Observou-se ainda que, a produção deveria ser contínua para garantir uma produção sem prejuízos, já que a produção não pode parar a matéria prima e a mão de obra também não poderiam faltar.

A partir disso surgem mudanças nas relações de produção, o comercializador dos produtos que comprava diretamente do agricultor e as vendia, começa a produzir as mesmas, comprando a matéria prima e o trabalho humano para a produção de tais produtos. Transformam-se assim, a terra e o trabalho em mercadoria. Isso significa a desarticulação da vida social, pois a sociedade se encontra submissa ao mercado, tornando comercializável a própria atividade humana e, com ela, parte da natureza explorada. (POLANYI, 2000, p. 97).

Sob a hegemonia do capital vislumbram-se as vias do desenvolvimento. Destarte, ao se promover o discurso do desenvolvimento a uma linguagem jurídica, os direitos comuns foram sendo destruídos (THOMPSON, 1998, p. 115). Isto se explica porque o direito comum era visto como um obstáculo ao desenvolvimento, pois se todos tivessem sempre direitos iguais sobre a terra ninguém iria querer trabalhá-la ou nela investir. Assim, deveria promoverse a individualização dos direitos, para que houvesse um melhor investimento na terra.

Durante o século XVIII, os tribunais decidiam em favor dos direitos comuns, mas com a disseminação do discurso do desenvolvimento, até mesmo os próprios indivíduos que 
tinham direito a terras comunais, despertaram interesse em restringir o acesso a esses direitos, passando a reivindicar que os tribunais os limitassem. Nesse processo histórico, o direito e o costume da época perdem para o desenvolvimento - incentivado o capitalismo - e quando ocorre a individualização total, a terra torna-se mercadoria, sendo desvinculada do indivíduo.

No Brasil, o cenário econômico internacional vivido antes da Revolução de 1930 era de uma produção agrária voltada para a exportação e as plantações eram baseadas basicamente na monocultura, em sua maioria para produzir café e açúcar em larga escala. Havia uma forte dependência do mercado internacional, o que gerava obstáculos ao desenvolvimento na formação de uma forte indústria nacional durante o século XIX.

Com a crise do liberalismo e a quebra da bolsa de valores de Nova York em 1929, se inicia uma crise econômica mundial, na qual urgia que o Brasil reformula-se sua economia, pois o mercado internacional para o qual estava acostumado a vender suas mercadorias estava em dificuldades financeiras e com isso poderia ter problemas perdendo seus produtos sem exportá-los. Mas, de maneira contrária, foram exatamente as economias agrárias regionais que criaram as condições básicas necessárias para a industrialização nacional na passagem do século XIX para o século XX.

Até a década de 1930, o Brasil manteve-se com a principal atividade econômica e fonte de riqueza, a produção agrícola. Porém, durante a Primeira Guerra Mundial, em razão das dificuldades impostas pelo conflito no mercado internacional, tanto na exportação quanto na importação, o Brasil viu-se obrigado a substituir as importações pelos produtos nacionais. Essa pressão incentivou o desenvolvimento da produção interna de bens industrializados e ainda colaborou para o crescimento das economias e das cidades vinculadas a indústria.

\section{$1 \mathrm{O}$ desenvolvimento da terra como mercadoria}

A apropriação da natureza para subsistência dá-se desde os primórdios da existência humana. Com o desenvolvimento, houve a necessidade de transformar-se o trabalho, a terra e o dinheiro em mercadoria, porém isso não podia ser algo natural, pois semanticamente mercadoria é algo que se produz para ser comercializado, e nem o trabalho, terra ou dinheiro foram produzidos para a venda, então, nenhum deles poderia ser realmente mercadoria, em verdade, eles foram gradualmente gerados pelas necessidades da atividade industrial (POLANYI, 2000 p. 97). 
O discurso do mercado como uma entidade auto-regulável exige toda uma organização social que opere segundo as leis de mercado, nesse caso, a produção em sua totalidade deve estar voltada para a venda no mercado e a totalidade dos rendimentos derivam de tais vendas. O mercado auto-regulável é uma inversão completa do caminho do desenvolvimento, é dizer que toda produção é para venda.

Há mercados para todos os bens e serviços, cujos valores se medem pelo preço da mercadoria, e para todos os demais componentes da indústria, como o trabalho, a terra e o dinheiro, sendo os preços destes o salário, o aluguel e os juros, respectivamente, sendo assim considerados mercadorias, pois, sem isso, seria impossível o estabelecimento da sociedade de mercado, da economia de mercado e do mercado auto-regulável.

A apropriação da terra como mercadoria é completamente fictícia, pois esta não foi concebida inicialmente para troca ou venda, precisando transformar-se para isto. Separandose assim a terra do indivíduo, uma vez que tradicionalmente a terra e o trabalho encontram-se unidos. O uso da terra impacta a natureza como um todo e a terra é apenas outro nome para a natureza que não é produzida pelo homem, embora a natureza não seja mercadoria, é impossível separá-la da terra. Ao propagar sua ideia clássica de terra como mercadoria fictícia ressaltando que o que chamamos de terra "é um elemento da natureza inexplicavelmente entrelaçado com as instituições do homem" (POLANYI, 2000, p. 214), tradicionalmente a terra e o trabalho não são separados.

Pode-se dividir o processo da terra como mercadoria em três aspectos, o primeiro é a comercialização do solo, o que promoveu uma mobilização do rendimento da terra. $\mathrm{O}$ segundo é o incremento da produção de alimentos e de matérias-primas orgânicas para atender às exigências, em escala nacional, de uma produção industrial em rápido crescimento. Já o terceiro é estender esse sistema de produção excedente aos territórios de além-mar e coloniais, o que levou a terra e sua produção a se inseriram no esquema de um mercado autoregulável.

Destaca-se que para os liberais, a justificativa da capacidade de uma economia de mercado repousa na ideia de que até a década de 1890 a fronteira estava aberta e havia muita terra disponível, era farto o abastecimento da mão de obra de baixo padrão e não havia qualquer compromisso de manter os câmbios estrangeiros estáveis (POLANYI, 2000, p. 270). Dessa forma, havia livre oferta de terra, trabalho e dinheiro, portanto não existia um mercado auto-regulável. Mas, no momento em que essas condições mudaram, a proteção social 
começou a fazer-se necessária. Com a relativa falta de mão de obra e como o solo e os recursos naturais se tornaram escassos, tinham que ser poupados. Assim, o sistema de mercado não é mais compreendido como auto-regulável, uma vez que ele não incorpora o trabalho, a terra e o dinheiro.

\section{0 desenvolvimento a partir da Revolução de 1930}

Como brevemente foi explanado na introdução, no Brasil e no todo mundo, havia uma depressão econômica antes de 1930, que significou a ruptura com o antigo modelo político que tinha as oligarquias agrárias no domínio da economia brasileira, considerado por alguns como a "crise do Estado oligárquico brasileiro" (VICENTINO e DORIGO, 1997, p. 348).

Num mundo cada vez mais conturbado pela crise econômica mundial e com sinais evidentes de aguçamento de conflitos internacionais, a preocupação com o autoabastecimento, com a garantia de alimentos para o país, é crescente. Nesse sentido, colonizar, produzir mais, e para o mercado interno, torna-se uma meta do Estado. (LINHARES e SILVA, 1999, p. 113).

Os grandes monopólios foram a maneira de o capital ter controle do mercado externo, porém acabou excluindo o capitalista médio do processo. O capitalista médio seria necessário para o abastecimento interno após a crise e precisariam das policulturas para alimentar a população, "valorizando a produção de alimentos e sugerindo a formação de núcleos coloniais policultores". (LINHARES e SILVA, 1999, p. 105).

A partir de 1930 a prioridade passa a ser então a de desenvolver um processo industrial brasileiro, rompendo com o modelo antigo de produção agroexportadora e das monoculturas cafeeiras (IANNI, Apud. KANAAN, 2004, p. 1). A Revolução de 1930 foi um marco histórico no Brasil, trazendo um novo paradigma através dos estudos e debates feitos por vários setores da sociedade e neles o tema central era o desenvolvimento industrial e urbano do Brasil, visando sanar os problemas que impediam esse avanço. Nas palavras de Getúlio Vargas:

O problema econômico pode-se resumir numa palavra - produzir. Produzir muito e produzir barato, o maior número aconselhável de artigos, para abastecer os mercados internos e exportar os excedentes das nossas necessidades. Só assim poderemos dar sólida base econômica ao nosso equilíbrio monetário, liberando-nos, não só dos 
perigos da monocultura, sujeira a crises espasmódicas, como também das valorizações artificiais, que sobrecarregam o lavrador em benefício dos intermediários. (Apud. LINHARES e SILVA, 1999, p. 106).

Dessa forma, nota-se que na Revolução de 1930 a visão era voltada para a agricultura, onde ocorre uma reorientação visando o mercado interno, visto que o mercado externo encontrava-se em crise, o objetivo era diminuir a dependência internacional, valorizar a produção de alimentos nacionais - com um viés claramente fordista de minimizar os custos e maximizar a produção - e a criação de núcleos coloniais com policulturas.

A política fordista-keynesiana foi difundida tanto no governo de Getúlio Vargas como no governo de Juscelino Kubitschek, esta era uma política de produção em massa para fortalecer o mercado interno e ao mesmo tempo de criação de meios de proteção ao trabalhador.

Assim, no período de 1930 a 1964 que se inicia realmente uma política de industrialização do Brasil, na qual, para alguns foi a Revolução Industrial do Brasil, mas não que antes não houvesse qualquer industrialização, só que até então não havia uma indústria estatal verdadeira e nem mesmo uma política clara de que isso seria o destino do país. A perspectiva nesse período era voltada para o desenvolvimento e não na buscar de um caráter social para isso.

Dessa forma, faz-se necessário a subdivisão deste tópico a dois períodos marcadamente relevantes para a questão do desenvolvimento do Brasil, o governo de Getúlio Vargas e de Juscelino Kubitschek.

\subsection{O Governo de Getúlio Vargas}

Adentrando propriamente nos períodos em que Getúlio Vargas esteve no poder, sem muitos detalhes, mas traçando um panorama sobre suas contribuições no desenvolvimento do país, pode-se afirmar que ele foi um político inovador e que deu um novo caminho para a economia brasileira. Vargas tinha características de um discurso fascista, por conta do nacionalismo por ele implantado e defendido, como também pelo uso que fazia da imprensa e propaganda a seu favor.

Em 1930, com o golpe de Vargas, ocorre a tomada de poder do país das mãos da elite oligárquica, paulista e cafeicultora em sua grande maioria, fazendo com que estes perdessem 
um pouco do poder político que detinham, porém ainda permaneceram poderosos economicamente e localmente. Assim, pretendia-se mudar a economia brasileira, transformando-o em um país independente, por meio do incentivo a industrialização nacional através de uma política nacionalista.

A política global de desenvolvimento de Vargas foi para "[...] desenvolver uma massa urbana capaz de servir de mercado de consumo para bens não-duráveis e principalmente alimentos, base para a constituição de um mercado auto-sustentável." (LINHARES e SILVA, 1999, p. 107). Mas, a política de Vargas se esbarra com o problema do campo, que era "caótico, desigual e concentrador" (LINHARES e SILVA, 1999, p. 109) e não seria fácil promover a modernização industrial sem uma resposta efetiva do campo.

Uma opção que Vargas tinha para o campo, evitando contrariar muitos interesses, era de erguer uma base sólida na área urbana e fabril, vencer os obstáculos dessa nova regulação e das cidades ganhar o campo.

A elite de latifundiários que dominará a economia brasileira desde o império, ainda era poderosa. Vargas mesmo diante do novo Estado dotado de autonomia, não poderia afrontá-los diretamente por meio de uma reforma agrária para melhor distribuir as terras, a reforma até chegou a ocorrer com algumas desapropriações por utilidade pública, bem timidamente, mas com prévia indenização, que poderia ser de dez a vinte vezes do preço pago no último imposto. (LINHARES e SILVA, 1999, p. 125 e 127). “Assim, sem se ocupar com a questão da terra na área próspera e já densamente ocupada do eixo Centro-Sul, a atuação do Estado, a partir de 1930, voltar-se-ia para os espaços vazios do Centro-Oeste, as áreas deprimidas do Nordeste e a imensa Amazônia.” (LINHARES e SILVA, 1999, p. 114).

Como a maior concentração dos latifúndios eram na região do Sudeste, no Oeste havia um sertão, pois era um enorme vazio demográfico. Vargas ao ver o cenário internacional perigoso de invasões a outros países e etc., precisava estabelecer uma medida segurança nacional, assim, volta seus olhares para as terras do Centro-Oeste. Evitando mais intrigas em seu governo, decide por adotar a primeira Marcha para o Oeste como solução, a fim de povoar o interior do país e criar as pequenas e médias propriedades, incentivando dessa forma o mercado interno.

Há uma nova visão para a agricultura, valorizando-se as pequenas e médias propriedades, e as tão sonhadas cooperativas, que em verdade não puderam ser colocadas em prática no Brasil. Vargas queria também acabar com a monocultura, pois uma nação não pode 
viver de apenas alguns tipos de alimento, precisava de um redirecionamento da agricultura, voltada para a policultura, para tornar o mercado interno autossuficiente e auto-regulável, abastecendo as cidades, e com a produção e o consumo interno o investimento permanecia dentro do país.

Um dos objetivos de Vargas era criar uma indústria nacional autossuficiente, baseada no consumo interno, sendo seu governo claramente nacionalista, voltado para o incentivo interno, na indústria e na urbanização nacional. Um exemplo desse nacionalismo foi a política de valorização do café, com a compra e queima do produto não vendido no mercado externo, isso para manter a economia brasileira funcionando e suas consequências foram benéficas. (VICENTINO e DORIGO, 1997, p. 351). Com o passar do tempo, agora os consumidores "[...] procuravam fontes brasileiras para produtos que, anteriormente, compravam no exterior. Ao mesmo tempo, os investimentos, desviados para o setor de exportação, eram atraídos pelos lucros cada vez mais altos advindos da produção industrial.” (SKIDMORE, Apud. VICENTINO e DORIGO, 1997, p. 352).

Com esse incentivo a criação de uma massa trabalhadora para as indústrias, ocorre o êxodo rural, e com ele há uma importância ainda maior na agricultura para o abastecimento do mercado interno das cidades, visto que agora grande parte da população concentra-se na área urbana esta passa a ser dependente das produções da área rural. A terra, antes vista apenas como o meio natural, passa depois de Vargas a ter um símbolo fundamental para a economia, para a integração nacional e para o desenvolvimento, isso se vê claramente por meio da primeira Marcha para o Oeste.

A Marcha não se dava pura e simplesmente em chamar a população oferecendo-lhes terras, deveria haver um incentivo ao cultivo e a plantação diversificada (policulturas), precisava-se também de construir estradas para ligar os Estados entre si, para que houvesse a produção de alimentos e sua distribuição, evitando-se assim o desabastecimento.

Em 1943 com a Marcha para o Oeste - primeira política estatal de ocupação de terras - ocorre a expansão do capital no campo, a preservação do campesinato, surgem as pequenas propriedades e é quando nasce a nação brasileira verdadeiramente, isto é, o "brasileiro" aquela junção de raças, e isso tudo impacta na questão agrária com a criação da fronteira aberta, fazendo com que o capital vá se "especializando", tomando espaço.

O programa da Marcha para o Oeste se justifica, pois, além de atender às necessidades do novo tipo de acumulação que se implantava no Brasil, baseado no 
crescimento do mercado interno e no favorecimento do setor industrial, cumpria as seguintes funções: politicamente, serviria para dirigir correntes migratórias, [...] ideologicamente, tornar-se-ia instrumento de defesa e [...] segurança nacional. (SILVA, 2005, p. 143).

Em seu governo, Vargas cria vários Decretos, alguns para tentar impedir que os próprios latifundiários também não se aproveitassem da politica da Marcha para o Oeste e se apropriassem de mais terras para si, passou-se até a exigir-se a apresentação de "título de propriedade para a legitimação das posses” (LINHARES e SILVA, 1999, p. 127). Outros Decretos como o 21.418/32 até eliminavam impostos cobradas entre Estados e Munícipios, e outro como o Decreto-Lei 3.823/33 auxiliava nas campanhas de colonização.

Em 1937 quando Vargas dá um novo golpe estabelece duas frentes, uma agrária e uma industrial. Com a Consolidação das Leis do Trabalho (CLT) de 1943 por ele estabelecida, criam-se as primeiras medidas protecionistas para os trabalhadores, como salário mínimo, jornada de trabalho e etc.

No governo de Vargas, havia muito incentivo e dignificação ao trabalho, transformando-os em indivíduos produtivos, visando o desenvolvimento do país, era uma clara politica keynesiana, com prática fordista buscando o "trabalhismo desenvolvimentista" (LINHARES e SILVA, 1999, p. 132-133).

[...] o campo, com seu homem tradicional, passa a ser visto como um problema, uma questão, a do obstáculo ao pleno desenvolvimento do conjunto do país. Para os homens que assumem o poder na década de 1930, o desenvolvimento é sinônimo de indústria, de população bem alimentada, saudável e de erradicação do analfabetismo e de endemias. (LINHARES e SILVA, 1999, p. 125-126).

Nesse contexto, surge a questão agrária de como desenvolver o campo brasileiro, chamado de retrogrado por muitos, para "ajudar e participar do desenvolvimento nacional?" (LINHARES e SILVA, 1999, p. 126). O campo era visto como um obstáculo ao pleno desenvolvimento do país, mas, Vargas tinha como projeto nacional colocar a agricultura para servir de base no desenvolvimento de forma contínua e auto-sustentável.

Dessa forma, pela primeira vez no país, um governo era manifestamente antagônico à hegemonia agroexportadora e à política da monocultura, condenando a dependência internacional do país e sua conexão com o capitalismo no mundo. 
Ante esse cenário, a questão agrária desde 1945 até os dias de hoje é marcada pelo debate das ideias opostas dos grupos de esquerda e de direita com respeito a esse projeto de desenvolvimento conjunto do campo e da cidade.

Para alguns, com visões de esquerda, isso foi chamado de "dualismo estrutural", havendo feudalismo no campo e capitalismo nas indústrias. Em contrapartida, mesmo dentro dessas visões havia diferentes posições, para Caio Prado Júnior que era marxista, afirmou que “o campo não era de modo algum feudal ou atrasado, sendo o conjunto das relações de trabalho então existentes inequivocamente capitalistas." (LINHARES e SILVA, 1999, p. 141).

Para outros como José de Souza Martins não havia qualquer oposição que não pudesse ser superada das velhas estruturas agrárias com o novo modelo capitalista industrial. Os que tinham visões conservadoras davam ênfase aos aspectos técnicos em aumentar a produção agrícola pelas novas tecnologias, através dos Complexos Agroindustriais (CAIs) a oposição entre o campo e a indústria desaparece, tornando-se a atividade agrícola uma grande indústria.

Caio Prado Júnior, “difusor do ideário nacionalista” (MOREIRA, 2003, p. 169) era contra a política de colonização, preferiam que fosse trabalhada e implantada primeiramente a Reforma Agrária no Sudeste, regulando assim as terras e depois disso ir ocupando as demais terras do Brasil. A reforma para este era um meio visto para resolver as tantas injustiças na má distribuição de terras no Brasil, essa reforma foi até discutida nesse período, e era vista como uma ordem de desenvolvimento, porém não pode ser implantada devido aos grupos oligárquicos que se opunham fortemente. Já Osvaldo Aranha, que era um grande articulador durante a Revolução de 1930 e que foi Ministro do Interior e logo da Fazenda, estabelece a colonização como sendo de urgência nacional para haver o avanço no mundo rural brasileiro.

Prefere evitar conflitos abertos com o latifúndio tradicional ou intervir nas áreas
velhas [...] Assim, Vargas contrariava fortemente os interesses agrários, punha o
latifúndio sob controle, incentivava a colonização interna, limitava a expansão
latifundiária, promovia a pequena produção familiar na fronteira (o que, de certo,
contrariava os antigos interesses agrários), mas abstinha-se de promover, no
conjunto do país, a modernização da estrutura agrária ou mesmo uma reforma
agrária, deixando, assim, o latifúndio tradicional intocado. (LINHARES e SILVA,
1999, p. 129).

Se fosse enumerado o papel da agricultura após a Revolução de 1930 poderia-se dizer que ela veio para desempenhar as seguintes funções básicas: garantir o abastecimento de 
alimentos a população; aumentar a produção; patrocinar as importações; diminuir o preço da nascente produção industrial; povoar um vazio demográfico existente - garantindo segurança nacional frente ao quadro de insegurança internacional vivido; e, a geração de empregos. (LINHARES e SILVA, 1999, p. 126).

As medidas tomadas por Vargas para modernizar o acesso a terra era por meio da intervenção do Estado de maneira a superar o atraso, um exemplo dessa intervenção foi o Decreto 24.606/33 que extinguia o sistema de arrendamento de terras. Já no plano econômico, Getúlio Vargas se esforça para ampliar e fortalecer o mercado interno, elevando a capacidade aquisitiva das populações, garantindo assim, o consumo de uma parte maior dos produtos nacionais.

A legislação agrária Varguista marca claramente o surgimento de uma questão agrária no Brasil. O campo deixa de ser tratado como atividade natural, única possível do país, e passa a ter uma função em um programa de desenvolvimento nacional. Após a participação do Brasil na segunda Guerra Mundial e nas Conferências Internacionais que dai surgiram, tem-se como efeito uma profunda politização da questão do desenvolvimento econômico do país (LINHARES e SILVA, 1999, p. 138).

\subsection{O Governo de Juscelino Kubitschek}

O modelo de desenvolvimento industrial difundido por Vargas encontra impasse “[...] concentração de renda, obstrução das formas indiretas de salários [...], inflação elevada e queda do salário real, queda da taxa de acumulação no setor industrial, deterioração dos termos de intercambio internacional e a decorrente escassez de divisas" (LINHARES e SILVA, 1999, p. 157). Assim, duas soluções eram observadas, a chamada por alguns de desnacionalização (entreguista) era a de permitir a entrada do capital externo no país e a segunda nacionalista de desenvolver um capitalismo nacional independente, a segunda claramente foi a opção de Vargas. "Nessas condições, defrontava-se a industrialização com uma situação de impasse: ou expandir o mercado interno ou abrir-se ao mercado externo." (LINHARES e SILVA, 1999, p. 159).

Completamente o oposto de Vargas, o governo de Juscelino Kubitschek - que também será analisado sem muitos detalhes, mas tendo enfoque sua contribuição para o desenvolvimento do país - foi chamado, pela esquerda, de "entreguista", por entregar o país 
para o mercado internacional. Tanto isso é verdade que o mercado que mais cresceu no governo de Juscelino foi o mercado automobilístico, através do forte investimento do capital estrangeiro "são criadas condições ainda mais favoráveis para a instalação de sucursais de empresas estrangeiras no país. As montadoras de carro chegam para impulsionar a abertura de estradas que ligassem as mais distantes regiões do Brasil.” (KANAAN, 2004, p. 3).

Em seu governo, Juscelino Kubitschek como sucessor de Vargas, trás um grande desenvolvimento nacional. Seu programa de metas deu base a seu governo, usando de toda estrutura estatal para aplicá-lo. Nessa época, depois de tantos estudos e planejamentos dos governos anteriores, era a hora de se implantar o desenvolvimento planificado e com a ajuda do capital estrangeiro se pôs em prática o Plano de Metas. "Tal plano visou desenvolver e integrar plenamente as regiões produtoras do país.” (KANAAN, 2004, p. 3).

Com a segunda Marcha para o Oeste de novo tipo, baseado na construção de Brasília, que seria a nova capital do Brasil, agora no interior, foi um símbolo na sua política, investir no interior e no campo, ocorrendo como grande meta a integração nacional por meio da interiorização e da construção de estradas. Isso aprofundou o avanço do capitalismo, mas antes tinha que regularizar as propriedades, e assim o fez.

A segunda Marcha para o Oeste foi boa para o desenvolvimento do país fazendo com que o processo de industrialização e urbanização fosse acelerado, mas não resolveu os problemas sociais e as desigualdades no campo.

JK industrializa o país, porém fracassa na tentativa de integrá-lo. A construção de Brasília, localizada no estado de Goiás, para ser a sede do governo federal, foi uma destas tentativas. Até mesmo a industrialização durante seu governo ficou restrita à região Sudeste. JK também não se preocupou em desenvolver políticas que beneficiassem o pequeno produtor rural. (KANAAN, 2004, p. 4).

Quanto à visão dos progressistas frente às oligarquias latifundiárias era de crítica e pela defesa da industrialização. No governo de Juscelino o nacionalismo foi um movimento social e político de plena expansão e, para integralizar a economia, precisava-se investimento no país, pois havia falta de mecanismos de comunicação. "Um dos pontos de estrangulamento do desenvolvimento industrial, identificado pela equipe de JK, era a falta de comunicação entre as regiões industrializadas do sudeste e as zonas agroprodutoras do interior." (MOREIRA, 2003, p. 176). A integração nacional se dá através da malha rodoviária, 
principalmente para poder levar os produtos para todos, utilizando as matérias primas para gerar renda.

Durante o governo de Juscelino Kubitschek muito se discutia a respeito da reforma agrária, que era vista como uma política de desenvolvimento. A função social era um projeto de modernizar o campo através da produção por ela defendida, a reforma agraria seria uma penalidade do seu não cumprimento. O poder oligárquico em muito se opunha a essa reforma, mas em um:

[...] país de possibilidades imensas como o Brasil, a reforma agrária tem que ter por objetivo a formação de grandes unidades altamente produtivas, dotadas de assessoria técnica moderna, grandemente capitalizadas. No Brasil onde tudo é grande, a agricultura não pode ser pequena, não pode ser limitada nem em hectares, nem em extensão: tem que ser agricultura moderna, baseada em unidades de produção em tudo e por tudo comparáveis às grandes indústrias. No Brasil, pois, reforma agrária não pode ser divisão de terras, retalhamento de propriedades: tem que ser muito mais que isso, tem que ser industrialização da agricultura. (MOREIRA, 1998, p. 356 in FERREIRA e DELGADO, 2003, p. 179).

Os ruralistas preferiam a política de colonização do interior do país ao invés da política de reforma agrária, sempre a defendendo como sendo mais viável e inteligente (MOREIRA, 2003, p. 184), prova disso é o senador da época Emival Ramos Caiado, que representava uma família oligárquica do estado de Goiás, ter sido a favor da construção e mudança da capital para Brasília, pois a colonização era melhor para a manutenção de suas terras e o desenvolvimento lhes gerava benefícios e também o surgimento de mais mão de obra. "Nunca é demais falar que talvez sem a presença de Emival Caiado no Congresso Nacional, sem seu trabalho legislativo, Juscelino não teria condições legais para construir e instalar Brasília." (SANDES JÚNIOR, 2008, p. 1).

A crítica que se faz é em relação a diferente maneira de apropriação do solo de Kubitschek comparada com a Marcha para o Oeste de Vargas. Vargas queria combater o latifúndio e gerar uma integração física e também econômica de toda nação, dando melhores condições de vida e trabalho no campo para tornar essas pessoas consumidoras do mercado interno. Já Kubitschek incentivou a apropriação espontânea das terras nacionais, como também elevou os níveis econômicos e sociais no campo.

Dessa forma, Kubitschek queria apenas integralizar o país e esse processo de Marcha para o Oeste em seu governo, predominou a lei dos mais fortes, sendo os mais prejudicados os “posseiros, populações ribeirinhas e povos indígenas" (MOREIRA, 2003, p. 186) deixados 
completamente à margem da sociedade e, nesse processo, muitas terras ficavam sem qualquer regulamentação.

Na política de Vargas, são fechadas as portas do país e tenta não se envolver com a elite, se afasta dos ruralistas, mas também não os afronta diretamente, e prega um nacionalismo puro. Já na política de Kubitschek, este abre as portas do país para entrada do capital estrangeiro e se aproxima dos ruralistas, pregando um nacionalismodesenvolvimentista, através do projeto nacional-desenvolvimentista.

\begin{abstract}
A estratégia de Kubitschek merece o rótulo de "nacionalismo desenvolvimentista", e não simplesmente "desenvolvimentismo", tal a fórmula pela qual foi apresentada ao povo brasileiro. Reforçando os propósitos e as ações do governo havia um apelo ao senso de nacionalismo. Era o "destino" do Brasil tomar "o caminho do desenvolvimento". A solução a o subdesenvolvimento nacional, com todas as suas injustiças sociais e tensões políticas, devia ser a industrialização urgente. O sucesso da política econômica de Kubitschek foi o resultado direto de seu sucesso no sentido de manter a estabilidade política. Ele foi capaz de manter isso apenas por um tour de force político. O segredo residia na marcante habilidade de Kubitschek em encontrar alguma coisa para cada um, enquanto evitava qualquer conflito direto com seus inimigos. Este estilo político não envolvia mudanças fundamentais. Pelo contrário, Kubitschek se utilizava do próprio sistema a fim de ganhar apoio - ou em muitos casos "ajeitando" a oposição - para os seus programas. Isto significava capitalizar as alianças getulistas sem o autoritarismo ou o populismo dos quais Vargas lançou mão em vários estágios de sua carreira. (SKIDMORE, 1982, p. 207-208).
\end{abstract}

Naquele período, havia três frentes de interesses, a dos ruralistas; a da classe trabalhadora; e, a dos nacionalistas. Durante o governo de Kubitschek houve uma estabilidade, que se deu pela entrada do capital estrangeiro e pela aliança feita com a bancada ruralista. Kubitschek conseguiu o que pretendia em sua política, fazer a meta síntese, cinquenta anos em cinco, mas tirou da discussão a questão da reforma agrária e a colocou como uma "ficção".

\title{
3 Os impactos do desenvolvimento na atualidade socioambiental
}

Um dos impactos relevantes para o desenvolvimento do país foi o processo de expansão da fronteira agrícola, com a entrada do capitalismo no campo por meio da formação dos Complexos Agroindustriais (CAIs) a partir de 1960, no governo militar. O CAI surge a partir da junção da indústria com as fazendas, produzindo e extraindo a matéria prima para seu beneficiamento. 
Dessa forma, o CAI, segundo Muller (1989, p. 45) se define como "[...] um conjunto formado pela sucessão de atividades vinculadas à produção e transformação de produtos agropecuários e florestais". É também considerado um condicionamento técnico para o campo, pois com ela decorre uma redução nos preços dos produtos devido ao menor custo com o deslocamento ou frete da matéria prima para a indústria. E, por ter um menor custo, pode entrar mais barata no mercado e ter assim menos concorrência.

Os Complexos Agroindustriais como impacto no desenvolvimento, não são nada mais do que o capital urbano industrial investido na agricultura, a agricultura submetida à indústria. Consequentemente, por meio das agroindústrias têm-se a produção e extração em massa dos recursos naturais através de todos os tipos de defensivos agrícolas existentes, já que, devido à industrialização, ocorre uma mecanização no campo, com o uso de tecnologias para aumentar e acelerar a produção. Usa-se também a irrigação com bombas em rios e vários insumos agrícolas.

Assim, tem-se como impactos $\operatorname{positivos}^{1}$ da agroindústria: a) uma melhor qualificação do profissional do campo, que tem que apreender a lidar com aquele maquinário avançado; b) o aumento da produção agrícola, por meio de técnicas de aceleração da produção; c) redução dos preços das mercadorias, diminuindo assim a concorrência; e, d) para alguns a maior "praticidade" no consumo.

Já, em relação aos impactos negativos ${ }^{2}$ da agroindústria tem-se: a) o desenvolvimento do capitalismo no campo; b) o uso desenfreado do solo, sem qualquer tempo de descanso ou rotação; c) o uso de fertilizantes e agrotóxicos com impacto ambiental como, por exemplo, contaminação do lençol freático - e impacto social, em relação à saúde das pessoas - como, por exemplo, o consumo de água contaminada; d) o aumento do desemprego pela mecanização e menor necessidade de tantos trabalhadores no processo; e) florestas desmatadas, extinção de animas e alimentos escassos - como, por exemplo, a Amazônia sendo usada para pecuária; f) o aumento desenfreado pelo consumo; e, g) o distanciamento de uma possível reforma agrária.

Este último impacto negativo, do distanciamento da reforma agrária, merece atenção, pois antes esta era barrada principalmente pela bancada ruralista, mas hoje também se esbarra com todo capitalismo implantado no campo através do mercado internacional com as

\footnotetext{
${ }^{1}$ Observe-se que a lista aqui exposta representa um rol meramente exemplificativo, sem excluir qualquer outro impacto positivo.

${ }^{2}$ Da mesma forma, esta lista é meramente exemplificativa, não excluindo qualquer outro impacto negativo.
} 
empresas estrangeiras já instaladas no país. Em verdade, a desapropriação não é um problema para o capital, pelo contrário, se tudo pudesse ser desapropriado pela reforma agrária seria melhor para este, pois transformaria a terra em algo móvel, dinheiro.

Analisando essa questão da terra, pode-se dizer que nela existe um "problema", que é o de estacionar o capital inicial, em contrapartida na indústria aquele capital investido já começa a ser explorado (HARVEY, 1990, p. 361-374). Hoje o arrendamento vem como solução para isso, o dono da terra a tem como patrimônio, e o que a arrenda a tem como capital. Mas também existem aqueles que investem na compra da terra pensando na sua valorização e posterior venda.

Outro aspecto do desenvolvimento na atualidade agrária é o agronegócio, que é entendido como a associação da terra com a tecnologia e o trabalho assalariado - sendo que essa terra gera renda e lucro. Esse fenômeno se inicia desde 1943, mas tem seu grande impulso após 1964, podendo-se até afirmar que foi uma criação do regime militar.

Finalizando, outro ponto negativo do desenvolvimento foi o aumento da violência, da miséria, da fome e outros tantos problemas sociais vividos pela falta de organização estrutural que não foi feita oportunamente. "Assim, não só se invertia a relação campo-cidade, com o avanço da urbanização, como ainda começava a se alterar a paisagem urbana, com o surgimento de favelas e alagados povoados por gente expulsa do campo." (LINHARES e SILVA, 1999, p. 155). Pode-se dizer que o capitalismo no Brasil se expandiu reproduzindo a tradição, atingindo a todos e reprimindo os mais fracos do processo.

Por último, vale citar que os impactos negativos do desenvolvimento tem-se tentado frear através de reuniões mundiais para discutirem e produzirem convenções e tratados que regulem o tema, como por exemplo, em 1986 surge a Declaração das Nações Unidas sobre o Direito ao Desenvolvimento, em 1987 o Relatório de Brundtland, em 1992 a Declaração do Rio sobre Meio Ambiente e Desenvolvimento e até a atualidade o que mais vem ganhando notoriedade é o discurso de desenvolvimento somado ao adjetivo sustentável, que é nada mais do que desenvolver preservando os recursos naturais para as atuais e futuras gerações.

\section{Conclusão}

Ante o exposto, pode-se concluir que o desenvolvimento precisou transformar a terra em mercadoria. A propriedade privada da terra aparece quando esta se desgarra dos 
imperativos de subsistência e torna-se acessível ao mercado. As terras, antes comunais eram vistas como as terras indígenas de hoje, um atraso no que se refere à produção industrial. Além do mais, a propriedade privada da terra associada ao desenvolvimento, exigia que houvesse um domínio econômico, social e até mesmo jurisdicional sobre seus trabalhadores, o que fomentou ainda mais as divisões de classes pela luta da propriedade da terra.

Aprecia-se que a terra tem o poder de produzir renda, seja ela de localidade ou de fertilidade. Sendo a terra um bem irreproduzível e limitado, seu acesso depende de uma condição pré-existente, e infelizmente, mesmo que houvesse uma reforma agrária efetiva, não haveria terras suficientes para todos.

Pode-se dizer que, a renda que a terra produz resolve a questão de como a terra - que não é um bem produzido através do trabalho humano - pode ter um preço e ser até alienada. Nesse sentido, o que se compra ou vende não é propriamente a terra em si, mas na verdade o direito sobre sua renda, sobre os lucros futuros previstos. Com isso, o direito sobre a terra se converte em capital fictício (mercadoria fictícia). Assim, neste ponto, conclui-se que não existe uma contradição da renda da terra com o capitalismo, pelo contrário ela contribui na regulação do capital.

$\mathrm{Na}$ terra, tem-se também uma condição especial em relação à indústria, pois é o único lugar aonde uma tecnologia não exclui a outra, pelo contrário uma tecnologia sob a outra a melhora, já na indústria uma tecnologia exclui a outra. Com o avanço das tecnologias poderia se vislumbrar de que não haveria mais terras ruins, pois todas seriam boas por conta da tecnologia nelas investida, mas em verdade, a tecnologia não supera uma boa natureza própria da terra.

No tocante ao desenvolvimento no Brasil, propriamente a partir da Revolução de 1930, pode-se afirmar que esta foi um marco histórico e trouxe enormes avanços para o desenvolvimento industrial e urbano do país, com um redirecionamento da agricultura voltada agora para a satisfação do mercado interno - valorizando-se assim a produção de alimentos nacionais e a criação de núcleos coloniais policultores.

Dessa forma, tem-se no período de 1930 a 1964 uma real política de industrialização do Brasil, através da formação de uma indústria estatal verdadeira reinventando o destino do país. Porém, com esse avanço, a perspectiva era apenas voltada para o desenvolvimento, sem buscar qualquer caráter social nisso, colocando-se muito a perder seja no campo social, agrário e principalmente ambiental. 
Afirma-se que no desenvolvimento do governo de Getúlio Vargas a terra, antes apreciada só como um o meio natural de sobrevivência, passa a ser o símbolo fundamental da economia, da integração nacional e do desenvolvimento. $\mathrm{O}$ que foi claramente apreciado através do estudo da primeira política de Marcha para o Oeste.

Constata-se nesse cenário o surgimento da questão agrária, de fazer com que o campo brasileiro auxiliasse e participasse desse processo de desenvolvimento nacional. A questão agrária é até hoje marcada por debates de ideais opostos, seja por aqueles grupos que a vislumbram como uma oposição entre campo atrasado e a cidade capitalista, seja por outros que encontram a solução nos Complexos Agroindustriais, transformando-se a atividade agrícola em uma indústria propriamente dita.

Deduz-se que a agricultura, após a Revolução de 1930, desempenhou um o papel muito importante, de abastecimento da população; aumento da produção de alimentos; patrocínio das importações; diminuição do preço da produção industrial; povoamento do vazio demográfico; e, geração de empregos.

Sobre o desenvolvimento no governo de Juscelino Kubitschek se reconhece sua divergência de opiniões se comparado ao governo de Vargas. Kubitschek teve como política de desenvolvimento entregar o país ao mercado internacional (projeto nacionaldesenvolvimentista) como também se manteve aliado aos ruralistas, diferentemente de Vargas que tinha uma política de nacionalismo puro ao fechar as portas do país e se distanciar dos ruralistas tentando combater o latifúndio.

Com a segunda política de Marcha para o Oeste de Kubitschek, tendo como base a construção da nova capital em Brasília, percebe-se que foi um símbolo no desenvolvimento do interior e do campo, atingindo a meta de integração nacional e construção de estradas. Mas, isso aprofundou o avanço e entrada do capitalismo no campo e também não resolveu os problemas sociais e as desigualdades existentes no campo.

Compreende-se, como uma crítica ao governo de Kubitschek, que este, em oposição a Vargas - que pretendia acabar com o latifúndio e dar integração física e econômica a toda população com melhores condições de vida e trabalho - incentivou a apropriação de terras nacionais de forma espontânea, fortalecendo assim os latifúndios e elevando os índices de desigualdade econômica e social no campo, prevalecendo a lei dos mais fortes.

Com a expansão da fronteira agrícola e a entrada do capitalismo no campo através dos Complexos Agroindustriais, pode apreciar-se que seus impactos negativos superam os 
impactos positivos. Por fim, acredita-se que a verdadeira calamidade de uma civilização não advém da centralização do poder ou da planificação da economia, mas sim da submissão da vida das pessoas a sistemas frios e impessoais.

O desenvolvimento produziu benefícios, mas por outro lado gerou um declínio na vida cotidiana das pessoas, devido à devastação da natureza, ao surgimento de massas empobrecidas e à profunda mudança que se impôs a seus modos de vida. Assim, se conclui que o capitalismo avançou através do desenvolvimento no Brasil com diferentes características, não apenas gerando o quadro atual, mas também criando e recriando a tradição.

Por fim, aprecia-se que na atualidade já não se fala mais em desenvolvimento se este não estiver ligado a seu adjetivo sustentável, pois quanto maior for o desenvolvimento maior deverá ser a proteção ao meio ambiente e para a sociedade. O desenvolvimento não deve ser apenas um crescimento econômico e tecnológico, mas também uma forma de inclusão social, de sustentabilidade para o meio ambiente e de sustento para os países e indivíduos.

\section{Referências Bibliográficas}

HARVEY, David. La teoria de la renta. In: Los límites del capitalismo y la teoria marxista. México: Fondo de Cultura Económica, 1990.

KANAAN, Hanen Sarkis. Estado e planejamento econômico no Brasil de Octávio Ianni. Artigo de Revista UDESC - Florianópolis/SC, 2004. Disponível em: <http://www.revistas.udesc.br/index.php/percursos/article/download/1438/1211> Acesso e download em: 29/06/2019.

LINHARES, Maria Yedda e SILVA, Francisco Carlos. Terra Prometida: uma história da Questão Agrária no Brasil. Rio de Janeiro: Campus, 1999.

MOREIRA, Vânia Maria Losada. Os anos JK: industrialização e modelo oligárquico de desenvolvimento. In: FERREIRA, Jorge e Lucilia Almeida Neves. (orgs.) O Brasil Republicano: o tempo da experiência democrática - da democratização de 1945 ao golpe civilmilitar de 1964. Rio de Janeiro: Civilização Brasileira, 2003.

MULLER, Geraldo. Indústria e agricultura no Brasil: do latifúndio-minifúndio ao CAI; Formulações gerais sobre o CAI; A agricultura Brasileira no CAI. In: MULLER, Geraldo. Complexo Agroindustrial (CAI) e modernização agrária. São Paulo: Editora Hucitec, 1989. 
POLANYI, Karl. A Grande transformação: as origens de nossa época. $12^{\circ}$ ed. Rio de Janeiro: Elsevier, 2000.

SANDES JUNIOR. Homenagem à memória do ex-Senador Emival Ramos Caiado. Brasília, DF: Câmara dos Deputados - Detaq, 2008. Disponível em: <http://www.camara.gov.br/internet/sitaqweb/TextoHTML.asp?etapa=3\&nuSessao=092.2.53. O\&nuQuarto $=14 \&$ nuOrador $=1 \&$ nuInsercao $=0 \&$ dtHorarioQuarto $=14: 26 \& \operatorname{sgFaseSessao}=\mathrm{PE}$ $\% 20 \% 20 \% 20 \% 20 \% 20 \% 20 \% 20 \% 20 \&$ Data $=07 / 05 / 2008 \&$ txApelido=SANDES $\% 20 J \%$ DANI OR\&txFaseSessao=Pequeno $\% 20$ Expediente $\% 20 \% 20 \% 20 \% 20 \% 20 \% 20 \% 20 \% 20 \% 20 \% 20 \% 2$ $0 \% 20 \& d$ tHoraQuarto $=14: 26 \&$ txEtapa $=\mathrm{Com} \% 20 \mathrm{reda} \% \mathrm{E} 7 \% \mathrm{E} 3 \% \% 20 \mathrm{final}>$. Acesso em 21/05/2019.

SILVA, Ana Lúcia da. A Revolução de 30 em Goiás. Goiânia: Cânone Editorial, 2005.

SKIDMORE, Thomas E. Brasil: de Getúlio Vargas a Castelo Branco (1930-1964). Rio de janeiro: Paz e terra, 1982.

THOMPSON, E. P. Costumes em comum. São Paulo: Companhia das Letras, 1998.

VICENTINO, Claudio; DORIGO, Gianpaolo. História do Brasil. São Paulo: Scipione, 1997. 